\title{
Cell Interactions Regulate Dendritic Morphology and Responses to Neurotransmitters in Embryonic Chick Sympathetic Preganglionic Neurons in vitro
}

\author{
Beverly Clendening ${ }^{a}$ and Richard I. Hume \\ Department of Biology, Universily of Michigan, Ann Arbor, Michigan 48109
}

The influence of non-neuronal cells and interneurons on the morphological development of chick sympathetic preganglionic neurons (SPNs) and on the responsiveness of these neurons to the neurotransmitters GABA, glycine, and glutamate was studied. SPNs were retrogradely labeled with the fluorescent dyes dil and dio, then separated from spinalcord non-neuronal cells and interneurons by fluorescenceactivated cell sorting. SPNs were grown in culture, either alone or in coculture with non-neuronal cells alone, with interneurons alone, or with both of these cell types (control cultures). The responsiveness of SPNs to neurotransmitters was assessed by whole-cell recording, while cell morphology was assessed after intracellular staining with 6-carboxyfluorescein.

Cell size and morphology were affected by non-neuronal cells. In the absence of non-neuronal cells, SPNs had smaller cell bodies and fewer major processes, whether or not interneurons were present. In contrast, responses to the 3 neurotransmitters were affected by both non-neuronal cells and interneurons, but in ways that differed slightly for each transmitter. In the absence of both non-neuronal cells and interneurons, responses to all 3 transmitters were much smaller than in control cultures, with responses to glutamate most profoundly affected. The addition of either non-neuronal cells or interneurons slightly increased the amplitude of SPN responses to glutamate, but the level of responsiveness with either cell type alone was much lower than for SPNs grown in the presence of both cell types. The addition of interneurons also slightly increased the responsiveness of SPNs to GABA, but non-neuronal cells alone had no significant effect on the responses of SPNs to GABA. Finally, the glycine responsiveness of SPNs was raised to control levels when either non-neuronal cells or interneurons were added. These experiments demonstrate that, though interneurons can have a significant inductive effect on the re-

\footnotetext{
Received Mar. 5, 1990; revised Aug. 1, 1990; accepted Aug. 20, 1990.

We thank Susan Barry, Stephen Easter, Daniel Goldman, and Hylan Moises for helpful comments on the manuscript and Mark Cameron, Nancy Hall, and Patricia Bach for excellent technical assistance. The research was supported by NIH Grant NS2 1043 to R.H., Training Grants MH 14279 and HD 07274 to B.C., and National Institute of Mental Health Grant MH09682 to B.C. R.H. was a fellow of the Sloan Foundation during part of this work.

Correspondence should be addressed to Dr. Richard I. Hume.

a Present address: Department of Biology, B-022, University of California at San Diego, La Jolla, CA 92093.

Copyright $\odot 1990$ Society for Neuroscience $0270-6474 / 90 / 123992-14 \$ 03.00 / 0$
}

sponses of SPNs to neurotransmitters, not all of the changes in neurotransmitter responsiveness can be related to the formation of functional synapses.

Both peripheral and central neurons are influenced in many ways by interactions with other cells. The most dramatic of these interactions is the absolute dependence of some neurons on the presence of target and/or afferent cells for survival (Hamburger and Levi-Montalcini, 1949; Beaudoin, 1955; Hamburger, 1958; Prestige, 1967; Johnson et al., 1977; Davis et al., 1983; Calof and Reichardt, 1984; Okado and Oppenheim, 1984; Dohrmann et al., 1986; O'Brien and Fischbach, 1986a; Furber et al., 1987; Gallently et al., 1989). For example, neither motor neurons (CNS neurons) nor sympathetic ganglion cells (peripheral neurons) survive for more than a few days in vitro in the absence of target cells or target-derived trophic factors. In contrast, at least some sympathetic preganglionic neurons (SPNs) survive and have normal basic physiological properties when grown in culture in the absence of their target, sympathetic ganglion cells (Honig and Hume, 1986). The influence of afferents and nonneuronal cells on the survival of these cells, however, is unknown.

Other less dramatic interactions between cells in the nervous system include the effects of target, afferent, and non-neuronal cells on neuron size and morphology (Varon et al., 1977; Bergey et al., 1981; Mudge, 1981; Adler and Black, 1984; Denis-Donini et al., 1984; Banker and Waxman, 1988; Johnson et al., 1989), on the type and amount of neurotransmitter and neurotransmitter synthesizing enzymes (Black et al., 1971, 1974; Pattersun and Chun, 1974, 1977; Giller et al., 1977; Patterson, 1978; Brookes et al., 1980; Godfrey et al., 1980; Kessler et al., 1981, 1983; Kessler, 1984a,b), and on the number and distribution of neurotransmitter receptors (Anderson and Cohen, 1977; Bevan and Steinbach, 1977; Frank and Fischbach, 1979; Jacob et al., 1984; O'Brien and Fischbach, 1986c; Role, 1988).

The influence of cell-cell interactions on neurotransmitter receptors has been studied most thoroughly in synapses in the periphery. Junctional ACh receptors on muscle are known to be regulated in part by the presence of the motor-neuron terminals (Anderson et al., 1977; Burden, 1977; Jessell et al., 1979). Nicotinic ACh receptors on chick ciliary ganglion cells are regulated by both afferents and target cells (Jacob and Berg, 1987), and muscarinic $\mathrm{ACh}$ receptors on mammalian sympathetic ganglia are regulated, at least in part, by non-neuronal cells (Smith and Kcsslcr, 1988). Because of the difficulty of separating identified CNS neurons from the other cells with which they interact, 
less is known about the role of cell-cell interactions in the regulation of neurotransmitter receptors on CNS neurons.

Recently, some progress has been made in understanding the regulation of receptors on identified CNS neurons. O'Brien and Fischbach (1986c) demonstrated that embryonic chick motor neurons grown together in culture with other spinal-cord cells have increased responsiveness to glutamate when compared to motor neurons grown alone in culture. The induction appeared to be due to the presence of interneurons, and it affected both NMDA- and non-NMDA-type glutamate receptors. In contrast to the effect on glutamate responses, the responsiveness of motor neurons to the inhibitory neurotransmitters GABA and glycine was not affected by the absence of interneurons and non-neuronal cells. It is not known if the receptors that were not affected by interneurons or non-neuronal cells are regulated by some intrinsic mechanism, or if target muscle cells or some diffusible factor are involved. These possibilities could not be tested in this system because motor neurons have a strict trophic dependence on muscle and do not survive for more than $24 \mathrm{hr}$ in culture without muscle cells or medium conditioned by muscle. The regulatory effect of interneurons on the glutamate sensitivity of motor neurons was not mimicked by medium conditioned by spinal cord cells. This suggested that cell contact was required for regulation.

In the preceding paper (Clendening and Hume, 1990), we showed that, when SPNs from the spinal cord of embryonicday- 7 chick embryos are grown in dissociated cell culture with spinal-cord interneurons and non-neuronal cells, they become sensitive to the 3 amino acid neurotransmitters GABA, glycine, and glutamate. We also showed that multiple inhibitory receptors and multiple receptor sublypes for 1 neurotransmiller are regulated independently by these CNS cells. We wondered whether the amino acid receptors on these cells from the embryonic chick spinal cord would be regulated by afferents in a manner similar to embryonic chick motor neurons, and whether target cells and non-neuronal cells would influence the expression of any of these receptors on SPNs.

In order to study identified SPNs in vitro, we labeled them in vivo with either the red fluorescent dye $1,1^{\prime}$-dioctodecyl-3,3,3',3'tetramethylindocarbocyanine perchlorate (diI) or the green fluorescent dye $1,1^{\prime}$-dioctodecyl-3,3,3',3'-tetramethyloxycarbocyanine perchlorate (diO). Because SPNs could be specifically labeled with fluorescent dye, we were able to separate them from neighboring interneurons and non-neuronal cells by fluorescence-activated cell sorting. We then studied the responsiveness of SPNs to the amino acid neurotransmitters when SPNs were grown either alone in culture or in coculture with any 1 of the cell types with which they normally interact. We also tested some of the likely mechanisms underlying regulation. Early in this study, we noted that the different culture conditions also had dramatic effects on cell morphology. Therefore, we also made systematic measurements of some morphological characteristics of these neurons.

\section{Materials and Methods}

Control cultures. Control cultures consisted of mixed spinal-cord cells with labeled SPNs and unlabeled interneurons and non-neuronal cells. They were obtained by methods described in the preceding paper (Clendening and Hume, 1990). Cell density has been shown to influence the amount and type of neurotransmitter synthesized by some cells (Adler and Black, 1985; Zurn and Mudry, 1986). We thought it might have similar effects on the regulation of neurotransmitter receptors. Therefore, we tried to standardize cell density under different culture con- ditions as much as possible. Control cultures were plated at an initial density of $10^{5}$ cells per plate or 1000 cells $/ \mathrm{mm}^{2}$. Cell density on days postplating was greater because non-neuronal cells continue to divide in vitro.

Cell sorting. To obtain cultures highly enriched in SPNs, we separated labeled SPNs from virtually all unlabeled cells by fluorescence-activated cell sorting. For each cell sort, sympathetic chain ganglia from $30 \mathrm{em}-$ bryonic-day-7 chicks were injected with both $\mathrm{diO}(4 \mathrm{mg} / \mathrm{ml})$ and diI $(3$ $\mathrm{mg} / \mathrm{ml}$ ) suspended in absolute ethanol with $10 \%$ dimethyl sulfoxide (DMSO). Both dyes were used simultaneously because the emission spectrum of diI did not make it appropriate for use with the fluorescence detectors on the flow cytometer we used, and diO fluorescence was apparently bleached by the laser during the cell sort, making detection of diO-labeled cells in culture difficult after cell sorting. The cells were therefore sorted based on the emission spectrum for diO (bandpass filtered between 490 and $540 \mathrm{~nm}$ ) and visualized in culture based on their diI fluorescence.

After injection, the embryos were incubated for 12-20 hr in oxygenated Tyrode's solution. The medial half of each spinal cord was then removed as for the preparation of control SPNs in mixed spinal-cord cell cultures. The spinal-cord tissue was incubated in $0.1 \%$ trypsin in $\mathrm{Ca}^{2+}, \mathrm{Mg}^{2+}$-free Puck's solution for $15 \mathrm{~min}$ at $37^{\circ} \mathrm{C}$. The enzyme was quenched with muscle medium, then the tissue was rinsed several times with Puck's solution to remove all serum-containing medium. The spinal-cord tissue was triturated in Puck's solution, and the suspension was passed through a $50-\mu \mathrm{m}$ mesh to remove any undissociated cells and large debris. Cells were sorted in a Coulter Corporation EPICS Division 751 flow cytometer. The cytometer was equipped with a 5-W argon laser and was operated at $488 \mathrm{~nm}$ at a power output of $175 \mathrm{~mW}$. Sheath pressure was $13 \mathrm{psi}$, and the flow rate was maintained at 2000 cells per sec through the 76- $\mu \mathrm{m}$-tip aperture. The unit was equipped with the MDADS II (Multiparameter Data Acquisition and Display System). Prior to sorting, the lines of the flow cytometer were filled for $1 \mathrm{hr}$ with $5 \%$ bleach and $70 \%$ ethanol and then flushed with sterile physiological saline. Cells were sorted on the basis of the combination of forward-angle light scatter (FALS) and fluorescence intensity. The criteria to be met by a cell to be sorted was fluorescence intensity in the brightest $4-5 \%$ of the population and within 2 standard deviations of the mean in a normal distribution of FALS. Sorted cells were collected in a sterile tube containing neuron medium. The cells were centrifuged for $10 \mathrm{~min}$ at $750 \mathrm{rpm}$, counted, resuspended in neuron medium with $5 \%$ chicken embryo extract, and plated at a density of $10^{5}$ cells per plate $\left(1000 \mathrm{cells} / \mathrm{mm}^{2}\right)$. Eight $\mathrm{hr}$ after plating, $1.5 \mathrm{ml}$ neuron medium was added to each plate.

Experimental cultures. In some dishes, sorted SPNs were plated alone. These dishes will be referred to as SPN-alone cultures.

To test for the effects of non-neuronal cells, sorted cells were plated on a confluent layer of spinal-cord non-neuronal cells. Non-neuronal cells were prepared by repeated platings of medial spinal-cord cells. These cells were fed every $3 \mathrm{~d}$ with muscle medium (see below for constituents), which lacks many of the added nutrients of neuron medium. They were allowed to remain in culture for $10 \mathrm{~d}$ and were then scraped from the bottom of the culture plates, trypsinized, and replated. The combination of low-nutrient medium and loss by cell death of nondividing neurons with repeated plating resulted in cultures that had only flat polygonal cells that are characteristic of astrocytes (Fischbach and Nelson, 1977) by the third plating. To obtain cultures containing only SPNs and non-neuronal cells, 10,000-20,000 sorted cells were added to each plate of non-neuronal cells. These cultures will be referred to as SPN-NNC cultures.

To obtain cultures with only SPNs and interneurons, non-neuronal cells were eliminated from mixed spinal-cord cell cultures containing labeled SPNs by the addition of adenosine arabinoside (ARA-A) to the nutrient medium. ARA-A is a mitotic inhibitor. When it was kept in our culture medium throughout the in vitro period, at a concentration of $1 \mathrm{~mm}$, it eliminated most non-neuronal cells by the third day in vitro without affecting neurons. These cultures will be referred to as SPNINT cultures. In an attempt to standardize cell density, cells for this experiment were initially plated at $3 \times 10^{5}$ cells per dish to compensate for the loss of non-neuronal cells. However, because non-neuronal cells continue to proliferate in vitro, by day 7 , cell density in control cultures was much higher than in cultures treated with ARA-A. Even with the high concentrations of ARA-A (1 mM) used in these experiments, it was sometimes impossible to eliminate all non-neuronal cells. Some of these cultures therefore contained small patches of non-neuronal cells. Even 
in the worst cases, however, the number of non-neuronal cells in these cultures on day 5 in vitro was always less than $1 \%$ of the number of non-neuronal cells in control cultures, and by day 7 in vitro, SPN-INT cultures contained less than $5 \%$ of the number of non-neuronal cells found in control cultures. We used ARA-A to eliminate non-neuronal cells in these experiments rather than cytosine arabinoside (ARA-C), which is more commonly employed, because at the concentrations needed to eliminate non-neuronal cells, ARA-C was also toxic to nearly all of the neurons in mixed spinal-cord cell cultures.

It seemed possible that the process of sorting itself could alter SPN morphology and/or responsiveness of SPN to amino acid neurotransmitters. It also seemed possible that differences in viahility between subpopulations of cells could select for a subpopulation of sorted SPNs with an atypical morphology or altered responsiveness to 1 or more of the neurotransmitters. As a control for these possibilities, we added unlabeled medial spinal-cord cells, prepared at the same time as cells for sorting, back to sorted cells. A total of $9.0 \times 10^{4}$ unlabeled cells (containing both neurons and non-neuronal cells) were added to $1.0 \times$ $10^{4}$ sorted SPNs, and these were plated together. These cultures will be referred to as SPN-CONT cultures.

To test for the effects of target cells on SPNs, mixed spinal-cord cell cultures were plated together with sympathetic ganglion cells. The lumbosacral sympathetic chain was removed from 7-d-old chick embryos and incubated in $0.01 \%$ trypsin in $\mathrm{CA}^{2+}-, \mathrm{Mg}^{2+}$-free Puck's solution for $20-25 \mathrm{~min}$ at $37^{\circ} \mathrm{C}$. The enzyme reaction was quenched with muscle medium, and the ganglia were triturated in neuron medium. Five $x$ $10^{4}$ ganglion cells were plated in each dish along with $5 \times 10^{4}$ mixed spinal-cord cells (containing 500-1000 labeled SPNs). We plated these cells at a ratio of 50-100 ganglion cells to 1 SPN because, in vivo, ganglion cells far outnumber SPNs. Normal neuron medium was added to these cocultures. These cultures will be referred to as SPN-SGC cultures.

To test for the effects of neurotransmitter substances on the regulation of their respective receptors, specific antagonists were added to neuron medium at a concentration that completely blocked the activity of that agonist in normal SPNs grown in vitro (see Clendening and Hume, 1990). Each test antagonist (1 mM strychnine, $1 \mathrm{~mm}$ kynurenic acid, or 100 $\mu \mathrm{M}$ bicuculline) was dissolved in neuron medium and added to mixed spinal-cord cell cultures containing labeled SPNs. The antagonist was present in nutrient medium starting 4-6 hr after plating and continuing until the plate was used for recording. Medium was changed every day in these experiments. Before these cultures were used for recording, they were washed 5-7 times with external recording solution to ensure that all of the antagonist had been removed.

To test for the effects of cell contact versus the soluble factor in the regulation of neurotransmitter responsiveness, medium that had been conditioned by mixed spinal-cord cells (CM) was added to the normal nutrient medium of cultures containing only sorted SPNs. Medium conditioned by spinal-cord cells was collected from cultures of unlabeled medial spinal-cord cells. These cultures contained SPN, spinal interneurons, and non-neuronal cells. Fresh neuron medium was added to these cultures on day 4 in vitro, and the conditioned medium was collected on day 7 and frozen at $-20^{\circ} \mathrm{C}$ until it was used. Conditioned medium was added to cultures of sorted SPN by mixing with normal neuron medium in a ratio of 1:1. Medium was changed every day in these experiments.

As a test for the specificity of any inductive effect of interneurons on the responsiveness of SPNs to neurotransmitters, we cocultured sorted SPNs with lumbar dorsal root ganglion (DRG) cells. Some DRG cells are known to store and release glutamate from terminals in the dorsal horn (Fagg and Foster, 1983). Lumbar DRGs were removed from day8 chick embryos and incubated with $0.02 \%$ collagenase in Puck's solution for $20 \mathrm{~min}$ at $37^{\circ} \mathrm{C}$. They were then rinsed with serum-containing medium, resuspended in neuron medium, and triturated. The dissociated cell suspension was plated in an uncoated Petri plastic culture dish for $1 \mathrm{hr}$ to remove non-neuronal cells. Cells that did not adhere to plastic (DRGs and some non-neuronal cells) were replated onto polyornithine- and laminin-coated dishes at a density of $8.0 \times 10^{4}$ cells per dish. Twenty-four hr later, $2.0 \times 10^{4}$ sorted SPNs were added to each dish. The cultures were fed every other day with normal neuron medium. These cultures will be referred to as SPN-DRG cultures.

To test for the effects of spike activity on the regulation of neurotransmitter receptors, $500 \mathrm{~nm}$ tetrodotoxin (TTX) was added to normal neuron medium. At days 5-7 in vitro, all spike activity in SPNs could be blocked by 200 nM TTX. Before these plates were used for recording, they were washed 5-7 times in external recording solution to ensure that all of the TTX was removed.
Culture medium. Standard neuron-medium constituents are listed in Clendening and Hume (1990). Muscle medium used in making nonneuronal cell cultures consisted of Eagle's minimum essential medium, $10 \%$ heat-inactivated horse serum, $40 \mu \mathrm{g} / \mathrm{ml}$ conalbumin, $50 \mathrm{U} / \mathrm{ml}$ penicillin, and $50 \mu \mathrm{g} / \mathrm{ml}$ streptomycin.

Recording methods. Recording methods, solutions, and method of drug applications were identical to those described in Clendening and Hume (1990).

Cell counts and morphology. A Zeiss IM 35 microscope equipped with epifluorescence optics and a $40 \times$ water-immersion lens plus a $10 \times$ eyepiece was used for all cell counts and morphological studies. The diameter of the microscope field was approximately $450 \mu \mathrm{m}$. For studies of labeled cells, the field was illuminated with a $50-\mathrm{W}$ mercury bulb and viewed with a standard rhodamine filter set.

Twelve hr after plating, cultures of sorted cells were examined for purity of the sort. The total number of living cells, as judged by the smooth, phase-bright appearance of the cell body, were counted in 20 fields distributed throughout each dish of sorted cells. In the same 20 fields, the number of living dil-labeled cells were counted. Purity of the sort was expressed as (the number of labeled cells)/(total number of living cells) $\times 100 \%$.

To estimate cell size, we made measurements from the same cells that were used for recording. As one measure of the cell surface area, the capacitance of each cell was calculated from the averaged capacitative current response to 25 successive test pulses of $10 \mathrm{mV}$. Morphological measurements were made on a subset of the cells that were studied with electrophysiological methods. Data were taken from cells on days 5-7 in vitro and included a series of cells from each experimental class. To make these measurements, neurons were intracellularly stained by adding the fluorescent dye 6-carboxyfluorescein $(0.5 \%)$ to the standard internal recording solution. When the whole-cell configuration of the patch-clamp technique is used for recording, the internal recording solution dialyses cells. During recording, therefore, the fluorescent dye diffused into the cell, spreading throughout the cell body and into the major processes. We measured the cell-body diameter of the dye-filled cells with an ocular micrometer and also counted the number of primary processes projecting directly from the cell body.

Statistical tests. The statistical test used for comparing mean values of measurements under varying culture conditions was the KruskalWallis 1-way analysis of variance (ANOVA) by ranks (Kruskal and Wallis, 1952). This nonparametric statistic was chosen because the distributions were often not normal, and therefore, a $t$ test was formally not appropriate. However, when a Student's $t$ test was applied to the data, very similar results to those reported were obtained. All statistical calculations were made using the program sAs/sTAT. A $p$ value of $<$ 0.05 was considered significant, bul as noted in the Results, most manipulations that produced a change had $p<0.005$.

\section{Results}

Yield, purity, and viability of sorled cells

The thoracic sympathetic chain ganglia of stage 30-31 chick embryos were injected with the fluorescent dyes diI and diO. After allowing time for transport of the dyes to the cell bodies of SPNs, the spinal cord was prepared for fluorescence-activated cell sorting. The fluorescence-intensity criterion used for sorting was determined empirically by comparing the fluorescence distribution of cell suspensions from injected and uninjected embryos. Figure 1 shows 2 typical curves of the fluorescence distribution of spinal-cord cell suspensions. The curve in Figure $1 A$ was obtained from a suspension that contained diO- and diI-labeled SPNs; the curve in Figure $1 B$ was from a control suspension containing spinal-cord cells without labeled SPNs. A peak of fluorescence in the lower intensity range was present in the cell suspensions from both injected and uninjected embryos. This peak represented autofluorescent spinal-cord cells. The trailing end and smaller peak in the high-intensity range was present only in samples from injected embryos. The criteria for sorting were set to include only this trailing end. The entire trailing end included the brightest $4-8 \%$ of total cells, varying slightly between sorts. The percentage of SPNs obtained in het- 
erogeneous spinal-cord cell cultures is generally 2-6\% of the total population (Honig and Hume, 1986). The sorting windows were set to collect only the brightest $4-5 \%$ of the population of fluorescent cells, sacrificing some yield in return for higher purity.

For each sort, 30 hemicords were prepared, yielding about $3.6 \times 10^{7}$ cells after dissociation and filtration. Yield after sorting for both fluorescence and size criteria ranged from $4.0 \times$ $10^{5}$ to $7.5 \times 10^{5}$ cells. Yields after collecting, centrifuging through a BSA gradient to remove debris, and resuspension ranged from $1.5 \times 10^{5}$ to $6.0 \times 10^{5}$ cells. Most of the loss of yield probably occurred during collection. In addition, it is likely that some cells are damaged by the turbulent flow through the tubing and the $76-\mu \mathrm{m}$ aperture.

We had decided to standardize the plating density at $10^{5}$ cells per standard dish $\left(1000\right.$ cells $\left./ \mathrm{mm}^{2}\right)$. In the initial experiments with sorted cells, $1.0 \times 10^{5}$ cells were plated in each dish. However, we found that, $24 \mathrm{hr}$ after plating, only $40-50 \%$ of these cells had adhered to the bottom of the plate and put out processes. In later experiments with sorted cells, therefore, $2.0 \times$ $10^{5}$ cells were plated in normal-sized dishes, or $5.0 \times 10^{4}$ cells were plated in a smaller area. In cultures seeded with only sorted cells, 93-98\% of the viable cells were diI-labeled $24 \mathrm{hr}$ after plating. In most cases, the few unlabeled cells were attached to labeled cells. Unfortunately, some of the unlabeled cells were inevitably non-neuronal cells, which continued to proliferate in vitro. By day 7 postplating, some SPN-alone cultures contained small patches in which there were many non-neuronal cells.

\section{Composition of cultures under different experimental condilions}

We studied the viability, morphology, and neurotransmitter responsiveness of SPNs under 6 experimental conditions as described below.

(1) Control cultures contained labeled SPNs, and unlabeled interneurons, and non-neuronal cells from medial thoracic spinal cords. Initial plating density was $10^{5}$ cells per dish, including 1000-2000 labeled SPNs. However, because these cultures contained many non-neuronal cells that continued to proliferate in vitro, cell density was much higher by day 7 in culture.

(2) SPN-alone cultures, as described above, contained 9398\% labeled SPNs and a few unlabeled neurons and non-neuronal cells. Cell density $24 \mathrm{hr}$ after plating was approximately $10^{5} \mathrm{cells} /$ dish. Density on subsequent days in culture was variable, depending on the number of non-neuronal cells contaminating the sort.

(3) SPN-CONT cultures initially contained $10^{4}$ sorted SPNs plus $9 \times 10^{4}$ unlabeled medial spinal-cord cells (including unlabeled SPNs, interneurons, and non-neuronal cells). As with other cultures, density on subsequent days in culture was greater than $10^{5}$ because non-neuronal cells continued to proliferate in vitro.

(4) SPN-NNC cultures contained $10^{4}$ sorted SPNs on a confluent layer of non-neuronal cells from medial spinal cords. Figure $2 A$ is a phase-contrast photomicrograph of a field from an SPN-NNC culture at day 5 in vitro.

(5) SPN-INT cultures initially contained $3 \times 10^{5}$ mixed spinal-cord cells. By day 3 in vitro, most of the non-neuronal cells had been eliminated, and approximately $10^{5}$ cells remained in each dish. Some non-neuronal cells always survived the ARAA treatment, but the number of non-neuronal cells was usually only about $1 \%$ and never more than $5 \%$ of total cell number.
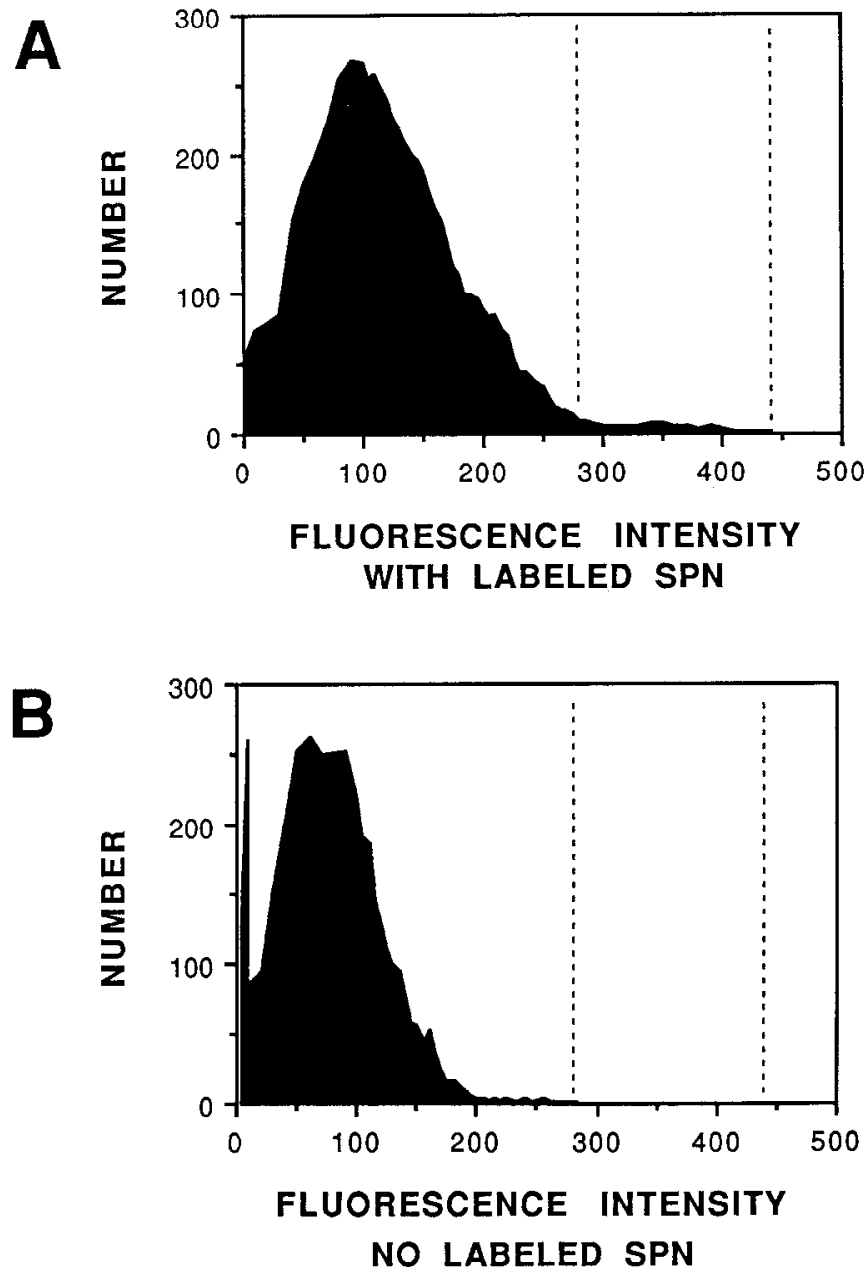

Figure 1. Fluorescence intensity analysis of suspensions of spinal-cord cells from injected and uninjected embryos. We used an EPICS 751 flow cytometer equipped with an argon laser operated at $488 \mathrm{~nm}$ and a Multiparameter Data Acquisition and Display System (MDADS II) to separate labeled SPNs from unlabeled cells. Fluorescence intensity in arbitrary units is shown along the abscissa in both histograms. The spinal-cord cells in $A$ were dissociated from the medial half of the spinal cord of day-7 embryonic chicks whose sympathetic ganglion chain between T1 and LS2 had been injected 16-24 hr earlier with the fluorescent dyes, dil and diO. Most of the cells in this suspension fell between 0 and 200 fluorescence units, but there was a trailing end to 450 units. The spinal-cord cells in $B$ were dissociated from embryonic chick spinal cords that had undergone all of the same procedures as those in $A$ except that the sympathetic ganglia were not injected with dye. The vast majority of the cells in this suspension fell in the first 200 fluorescence units; there was a small trailing end to approximately 275 units. The trailing end of brightly fluorescent cells (between 300 and 450) was only seen in the suspension of cells from injected embryos. The flow cytometer was programmed to select only cells whose fluorescence fell within this range. In this particular sort, this included $5.12 \%$ of the total population of medial spinal-cord cells.

Figure $2 B$ is a phase-contrast photomicrograph of a field from an SPN-INT culture at day 5 in vitro.

(6) SPN-DRG cultures initially contained $8 \times 10^{4} \mathrm{DRG}$ cells and $2 \times 10^{4}$ sorted SPNs.

(7) SPN-SGC cultures initially contained $5 \times 10^{4}$ sympathetic ganglion cells and $5 \times 10^{4}$ mixed spinal-cord cells with $500-$ 1000 labeled SPNs. 


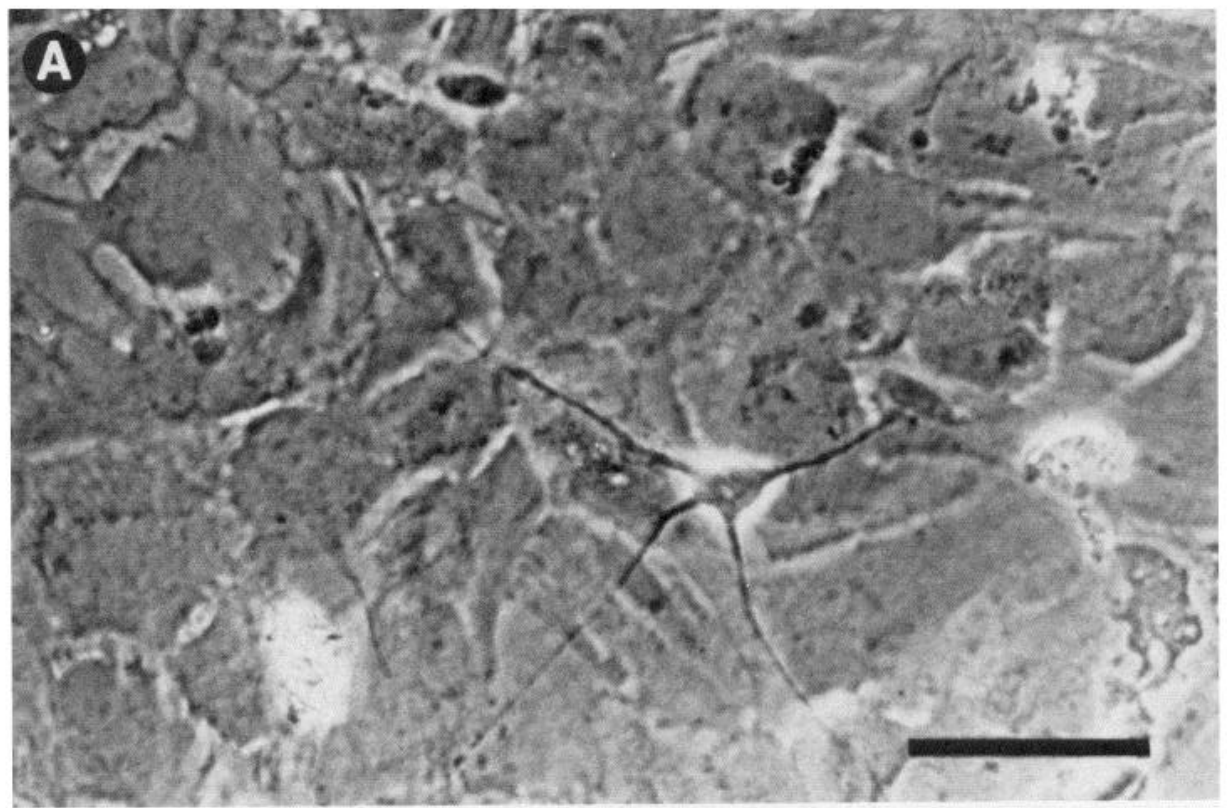

Figure 2. Cultures of preganglionic neurons with only non-neuronal cells or only interneurons. $A$, Phase-contrast micrograph of a field from a culture containing approximately 20,000 sorted SPNs grown on a confluent layer of non-neuronal cells (SPN-NNC cultures). The sorted cells had been plated 7 days earlier. $B$, Phase-contrast micrograph of a field from a culture of labeled SPNs and interneurons (SPN-INT cultures) on day 7 in vitro. There are virtually no non-neuronal cells in these cultures. Scale bar, $100 \mu \mathrm{m}$.

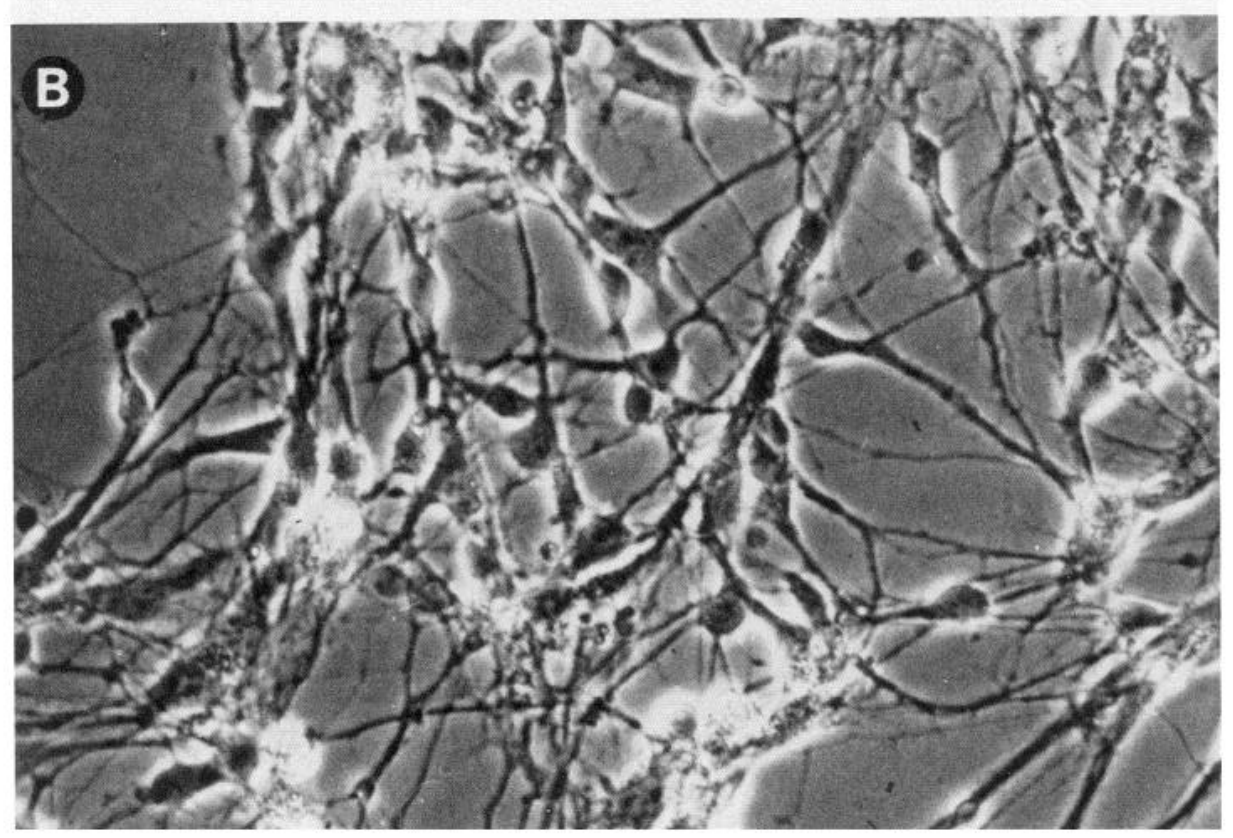

\section{Viability of SPNs under various culture conditions}

Many different types of neurons have been shown to be absolutely dependent on the presence of target cells or afferents for survival (Hamburger and Levi-Montalcini, 1949; Beaudoin, 1955; Hamburger, 1958; Prestige, 1967; Johnson et al., 1977; Davis et al., 1983; Okado and Oppenheim, 1984). Although the number of living SPNs in SPN-alone cultures decreased continuously with time in vitro, this attrition was not nearly as rapid or complete as expected for cells with a strong trophic dependence. At day 5 in vitro, the number of viable SPNs in SPNalone cultures was about $59 \%$ of number of viable SPNs counted at day 1 . This stands in contrast to the viability of cells such as motor neurons and sympathetic ganglion neurons, which are known to have a strong trophic dependence. When plated alone in culture, none of these cells survive past day 1 in vitro unless targets or target-derived factors are present. The fact that SPNs in vitro did not have a strong trophic dependence on their target was somewhat surprising because Johnson et al. (1977) had found rat SPNs to be dependent on the presence of targets for survival during development in vivo. The addition of sympathetic ganglion cells to mixed spinal-cord cell cultures improved the survival of SPNs slightly but not nearly as much as would have been expected if SPNs were strongly dependent on their target cells. Seventy-eight percent of viable SPNs at day 1 in coculture with sympathetic ganglion cells were still alive at day 5 , whereas only $63 \%$ of SPNs in mixed spinal-cord cell cultures were still alive at day 5 .

The presence of non-neuronal cells also seemed to slightly enhance the survival of SPNs. At day 5, viability of sorted SPNs plated on a bed of non-neuronal cells was $83 \%$. In contrast, when non-neuronal cells were eliminated from cultures and SPNs 
Table 1. Morphological characteristics of SPNs under varying culture conditions

\begin{tabular}{|c|c|c|c|c|c|c|}
\hline \multirow{2}{*}{$\begin{array}{l}\text { Culture } \\
\text { condition }\end{array}$} & \multicolumn{2}{|c|}{$\begin{array}{l}\text { Cell-body diameter } \\
(\mu \mathrm{m})\end{array}$} & \multicolumn{2}{|c|}{$\begin{array}{l}\text { Number of } \\
\text { major processes }\end{array}$} & \multicolumn{2}{|c|}{ Capacitance (pF) } \\
\hline & Mean \pm SEM & $N$ & Mean \pm SEM & $N$ & Mean \pm SEM & $N$ \\
\hline Control SPN & $20.0 \pm 0.85 \dagger$ & 25 & $5.1 \pm 0.24 \dagger$ & 21 & $28.8 \pm 1.4 \dagger$ & 201 \\
\hline SPN alone & $9.9 \pm 0.75^{*}$ & 18 & $2.4 \pm 0.16^{*}$ & 23 & $16.5 \pm 1.2^{*}$ & 73 \\
\hline Sort-CONT & $22.2 \pm 0.97 \dagger$ & 25 & $4.3 \pm 0.28 * t$ & 24 & $30.6 \pm 3.4 \uparrow$ & 77 \\
\hline SPN-NNC & $18.9 \pm 1.1 \dagger$ & 39 & $4.7 \pm 0.31 *+$ & 36 & $25.6 \pm 1.6 \dagger$ & 80 \\
\hline SPN-INT & $12.0 \pm 0.84^{*}$ & 23 & $2.6 \pm 0.19^{*}$ & 11 & $21.8 \pm 0.93^{*} \dagger$ & 93 \\
\hline
\end{tabular}

Capacitance measurements were taken from all cells used for recording at day 7 in vitro for each experimental condition Cell capacitance was calculated from the averaged capacitative current response to 25 successive test pulses of $10 \mathrm{mV}$ each. Other measurements were made on cells that had been in culture for 5-7 d. These cells were filled with 6-carboxyfluorescein $(0.5 \%)$ by adding this dye to the internal recording solution; this facilitated the counting of major processes. Cells were viewed using a Zeiss IM 35 microscope equipped with a $40 \times$ water-immersion lens plus a $10 \times$ eyepiece. Cell-body size was measured using an eyepiece micrometer. All values were from 3 or more separate platings of cells.

*, Significantly different from control $(p<0.005)$.

$\dagger$, Significantly different from SPN alone $(p<0.005)$. All other comparisons were insignificant $(p>0.05)$.

were maintained with only interneurons, SPN viability was comparable to SPN-alone cultures, with only about $56 \%$ of viable cells at day 1 surviving to day 5 in vitro.

\section{Morphology of SPNS under various culture conditions}

Interactions between different cell types influenced not only SPN survival but also SPN size and dendritic morphology. The cellbody size, cell-surface area, and number of primary processes of SPNs were greater in the presence of non-neuronal cells than in their absence. Table 1 shows the mean cell-body size, mean capacitance, and mean number of major processes of SPN under the various experimental conditions. The mean value for each of these measurements was significantly lower for SPNs in SPNalone cultures than they were for SPNs in cultures of mixed spinal-cord cells or for SPNs grown only with interneurons ( $p$ $<0.0005$ ). In contrast, the diameter and capacitance for SPNs grown on preplated non-neuronal cells were not significantly different from values for SPNs in mixed spinal-cord cell cultures $(p>0.05)$. The mean number of processes on SPNs grown on preplated non-neuronal cells did pass the test of significance for differing from control mixed spinal-cord cell cultures; however, because the number of processes did not differ significantly from the sort-control cells, we consider this to be a spurious result. Figure 3 shows representative carboxyfluorescein-filled SPNs in mixed spinal-cord cell cultures (Fig. $3 A$ ), in cultures of SPNs and non-neuronal cells only (Fig. $3 B$ ), and in cultures of SPNs with interneurons only (Fig. $3 C$ ).

In summary, non-neuronal cells were important in the maintenance of cell morphology. When non-neuronal cells were absent from cultures, SPNs had smaller cell bodies and fewer major processes than when SPNs were grown in mixed spinal-cord cell cultures or when sorted SPNs were added to a confluent layer of non-neuronal cells.

\section{Responses of sorted SPNS to GABA, glycine, and glutamate}

Interactions between different cell types were important for the expression of normal responsiveness to all 3 amino acid neurotransmitters by SPNs. SPNs grown alone in culture were less sensitive to standard applications of GABA, glycine, and glutamate than were control SPNs in mixed spinal-cord cell cultures. Glutamate responsiveness was most profoundly affected. Table 2 shows the mean peak currents elicited by GABA, gly- cine, and glutamate at day 7 in vitro for SPNs in SPN-alone and control cultures. For each neurotransmittcr, the mcan pcak current evoked in cultures of SPNs grown alone was significantly smaller than the mean peak current in SPNs in control cultures $(p<0.0001)$. In the preceding paper (Clendening and Hume, 1990), we showed that, when SPNs are grown in control, mixed spinal-cord cell cultures, there is a striking developmental increase in the responsiveness to GABA, glycine, and glutamate. The low responsiveness of sorted cells represents a failure to increase neurotransmitter responsiveness, as if the cells became frozen at an early stage of development in the absence of other cells. The responsiveness of sorted cells grown alone at day 7 in vitro is very similar to that of control cells at day 2 in vitro. Mean peak responses of control SPNs to GABA, glycine, and glutamate at day 2 in vitro were $425 \pm 31,157 \pm 15$, and $9 \pm$ $4 \mathrm{pA}$, respectively. Mean peak responses of SPNs grown alone at day 7 in vitro were $464 \pm 45,165 \pm 21$, and $6 \pm 2 \mathrm{pA}$ for GABA, glycine, and glutamate, respectively.

As noted above, SPNs grown alone generally had smaller cell bodies, smaller cell capacitance, and fewer major processes than SPNs in mixed spinal-cord cell cultures. Might the lower responsiveness of sorted SPNs grown alone in culture be attributable solely to their smaller size? By this hypothesis, neurotransmitter responsiveness would be regulated by cell-cell interactions (because we showed above that such interactions regulate cell size), but the effects on neurotransmitter responsiveness would be secondary. When mean peak currents were normalized by capacitance (as a measure of cell-surface area), the normalized GABA and glycine currents in sorted cells were not significantly different from those of control SPNs in mixed spinal-cord cell cultures $(p>0.05)$, but normalized glutamate currents in sorted cells remained 30 -fold smaller than normalized currents in control SPNs $(p<0.0001)$. These data raise the possibility that GABA and glycine responsiveness is regulated by cell size, but rule out this possibility for glutamate responsiveness. However, neurotransmitter responsiveness bore little correlation with cell size (Fig. 4). Both large cells with small currents and small cells with large currents were present under all conditions. Below, we present additional information that indicates that the responsiveness of SPNs to GABA and glycine were regulated independently of cell size.

The data presented in Tables 1 and 2 also illustrate an inter- 

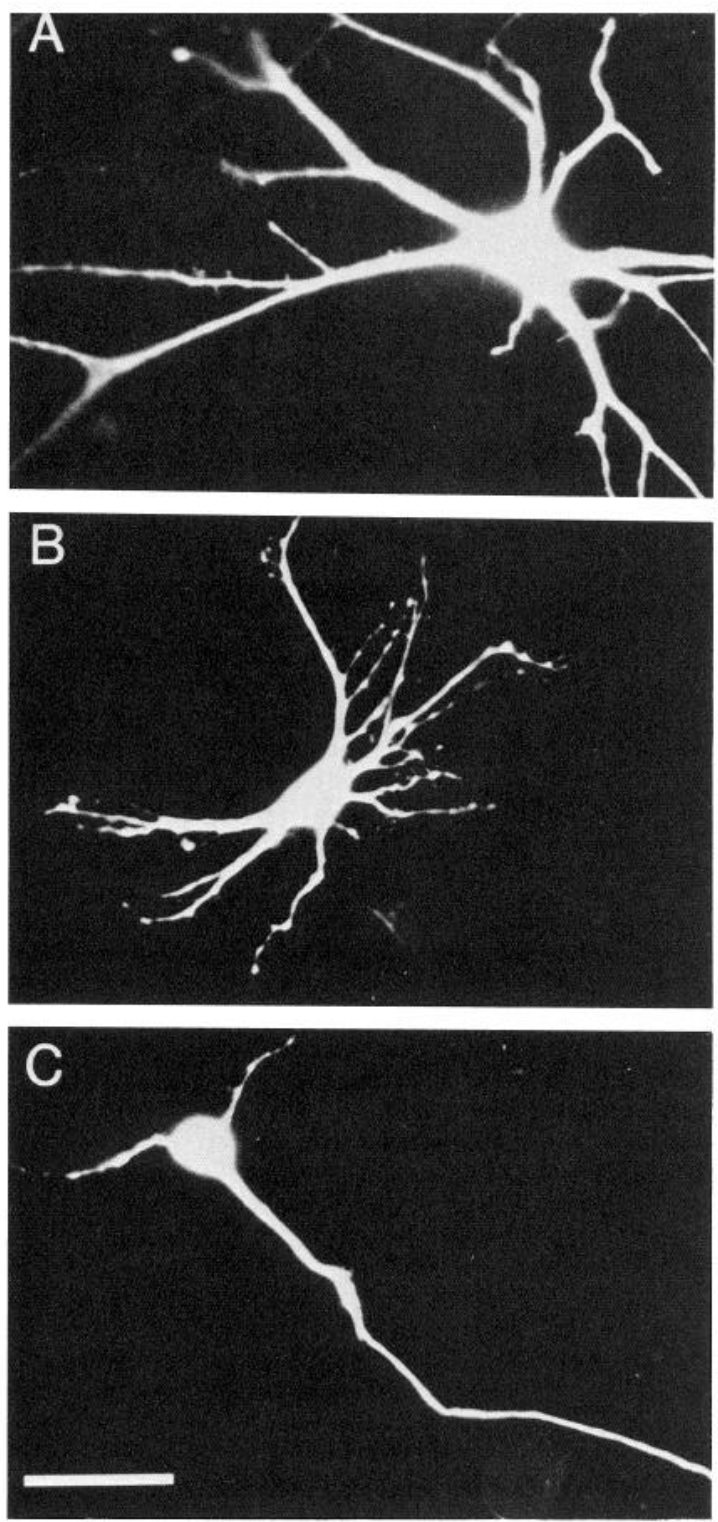

Figure 3. Morphology of preganglionic neurons under different culture conditions. Preganglionic neurons were identified in cultures based on their dil fluorescence. The patch pipettes used for recording from these cells were filled with standard internal recording solution to which 6carboxyfluorescein $(0.5 \%)$ was added. During recording, the internal solution with the fluorescent dye perfused the cells, diffusing into the cell body and proximal processes. Carboxyfluorescein-filled cells were used for counts of major processes. $A$, SPN in a culture of mixed spinalcord cells. $B$, SPN in a culture containing sorted SPNs and non-neuronal cells. $C$, SPN in a culture containing SPNs and interneurons (ARA-A treated). Scale bar, $50 \mu \mathrm{m}$.

esting anomaly. Table 1 presents mean cell capacitance for control and sorted cells, while Table 2 presents the mean currents and normalized mean currents for transmitter-evoked currents. Because normalized current for each cell was calculated by dividing its current by its capacitance, it was quite surprising that dividing the mean currents in the top of Table 2 by the mean capacitances given in Table 1 does not produce numbers equal to the mean normalized currents shown in the bottom of Table 2. One possible explanation of this anomaly was that the capacitance of cells responsive to glutamate was different from that of cells responsive to GABA and glycine. Indeed, the result
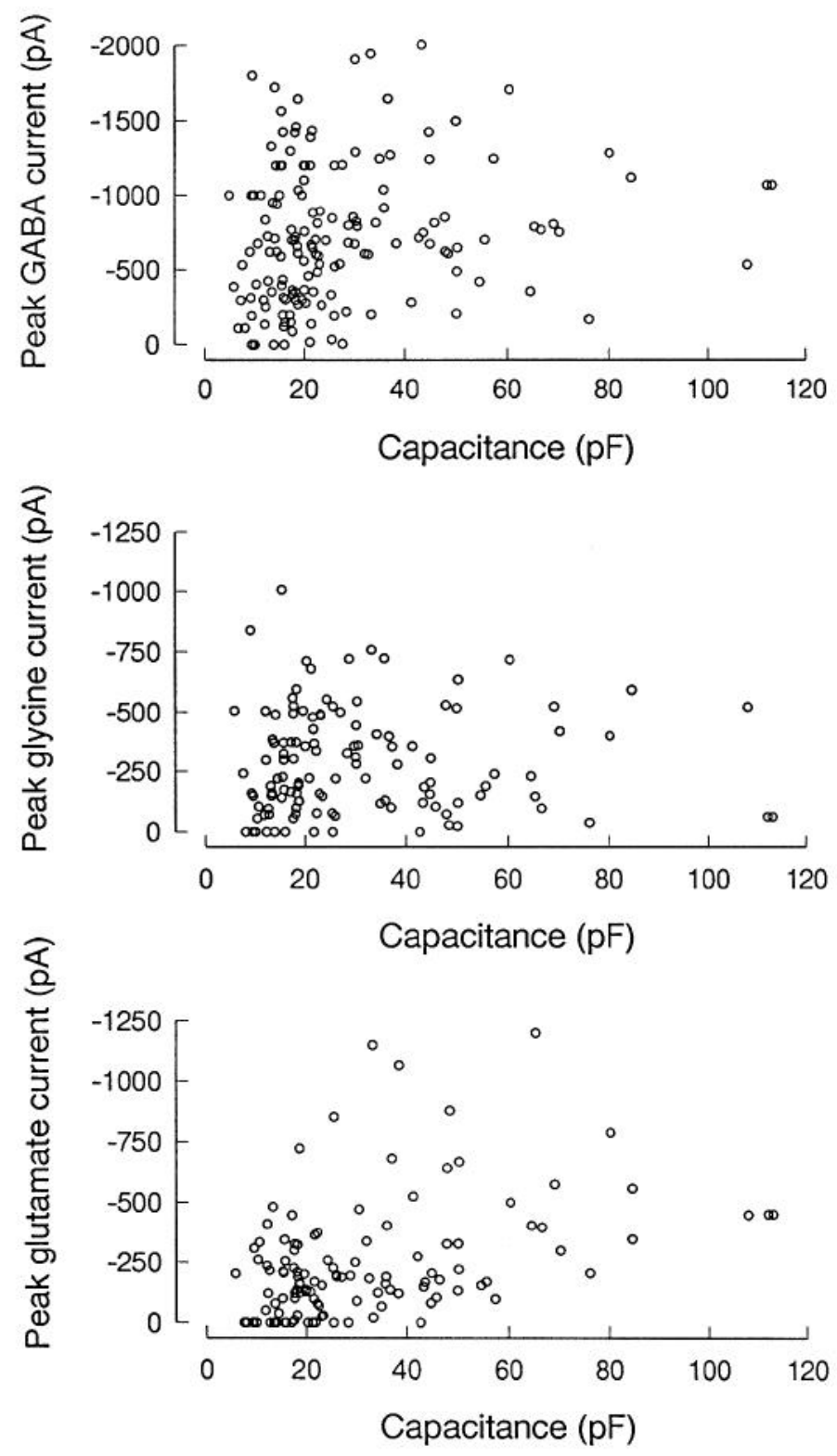

Figure 4. Responses of SPNs to GABA, glycine, and glutamate were not highly correlated with cell capacitance. Each point in these scatter plots is data for an individual cell. There was no obvious relationship between the capacitance and the response of the cells to any of the transmitters. Regression analysis confirmed the lack of a linear relationship. The coefficients of determination $\left(r^{2}\right)$ for correlation between capacitance and peak response to each of the transmitters were all less than 0.2 . These data were taken from SPNs at day 7 in vitro, but a similar lack of correlation was found at all ages studied and for all experimental treatments.

obtained by dividing the mean current by the normalized current for the data from each transmitter is very suggestive of this possibility. However, this was not the case. The mean and SE of the capacitances for the cells tested with GABA, glycine, and glutamate were $28.8 \pm 1.4,31.0 \pm 1.6$, and $32.9 \pm 1.8 \mathrm{pF}$, respectively, for control cells and $16.5 \pm 1.3,16.9 \pm 1.3,17.0$ $\pm 1.3 \mathrm{pF}$ for sorted cells, respectively, not at all the results suggested by the division. Why, then, does the seemingly simple exercise in division give misleading information? The explanation is that the distributions of transmitter responsiveness are skewed, rather than normal. The consequence of this skewing 
Table 2. GABA, glycine, and glutamate currents in cultures of SPNs alone and in control cultures

\begin{tabular}{lcclll} 
& \multicolumn{2}{c}{ SPNs alone } & & \multicolumn{2}{c}{ Control SPNs } \\
\cline { 2 - 3 } \cline { 5 - 6 } & Mean \pm SEM & $N$ & & Mean \pm SEM & $N$ \\
\hline Mean peak current $(\mathrm{pA})$ & $464 \pm 45^{*}$ & 73 & & $756 \pm 36$ & 201 \\
GABA & $465 \pm 21^{*}$ & 69 & & $335 \pm 25$ & 168 \\
Glycine & 165 & 70 & & $277 \pm 19$ & 173 \\
Glutamate & $6.1 \pm 1.8^{*}$ & & & \\
Normalized peak current $(\mathrm{pA} / \mathrm{p \Gamma})$ & & & \\
GABA & $35.4 \pm 5.1$ & 73 & & $34.6 \pm 2.2$ & 201 \\
Glycine & $12.2 \pm 1.7$ & 69 & & $14.9 \pm 1.3$ & 168 \\
Glutamate & $0.29 \pm 0.08^{*}$ & 70 & & $10.0 \pm 0.74$ & 173
\end{tabular}

Mean GABA, glycine, and glutamate currents were recorded in control SPNs and sorted SPNs grown alone in culture. All measurements were taken at day 7 in vitro. SPN-alone data were taken from 6 separate platings; control data were from more than 10 platings. Normalized currents were obtained by dividing the peak current response for each cell by the measured capacitance of that cell, then taking the mean of the data for all cells. Because capacitance is proportional to surface area, the normalized currents indicate current density.

*, Significantly different from control SPNs $(p<0.001)$. All other values were not significantly different from control $(p>0.05)$.

is that the small cells with large currents have a different weight in the calculation of the mean normalized current than they do in the calculation of the (mean current)/(mean capacitance). Because the data on normalized currents are potentially misleading, and because cell size was not a good predictor of the amplitude of responses, we present the rest of our data as peak currents, rather than normalized currents.

The sorting process itself was not responsible for the failure of neurotransmitter responsiveness to increase in SPNs grown alone (Fig. 5). By day 7 in vitro, sorted cells in SPN-CONT cultures had mean peak current responses to each neurotransmitter that were equal to or larger than those of SPNs from mixed spinal-cord cell cultures. In fact, the peak glycine currents recorded from SPNs in SPN-CONT cultures were actually larger than those of SPNs in control cultures $(p<0.001)$. We do not understand the significance, if any, of the increase in the responsiveness of SPNs in these cultures to glycine. Regardless of this unexpected result, the results indicate that the sorting process itself was not responsible for the decreased neurotransmitter responsiveness of sorted SPN grown alone in culture.

Regulation of GABA, glycine, and glutamate responsiveness by non-neuranal cells and interneurons

The observations on sorted SPNs grown alone indicated that both cell size and the responsiveness of SPNs to neurotransmitters were regulated by cell-cell interactions. To determine which of the 2 cell types, interneurons or non-neuronal cells, was responsible for these regulatory effects, we measured the cell size (Table 1) and the GABA, glycine, and glutamate responsiveness (Fig. 5) of SPNs grown with either interneurons only or with non-neuronal cells only. When SPNs were grown in culture with only non-neuronal cells, GABA currents re-

$\overline{\text { Figure 5. Mean peak currents in preganglionic neurons under various }}$ culture conditions: peak current responses of SPNs to $500-\mathrm{msec}$ puffer applications of $100 \mu \mathrm{M} \mathrm{GABA}, 250 \mu \mathrm{M}$ glycine, and $50 \mu \mathrm{M}$ glutamate under various cultures conditions at 7 days in vitro. CONTROL, mixed spinal-cord cell cultures; $S O R T-C N T$, sorted SPNs plated with unlabeled spinal cord cells; SPN ALONE, sorted SPNs grown alone; $S P N$ $N N C$, sorted SPNs plated on a confluent layer of non-neuronal cells;
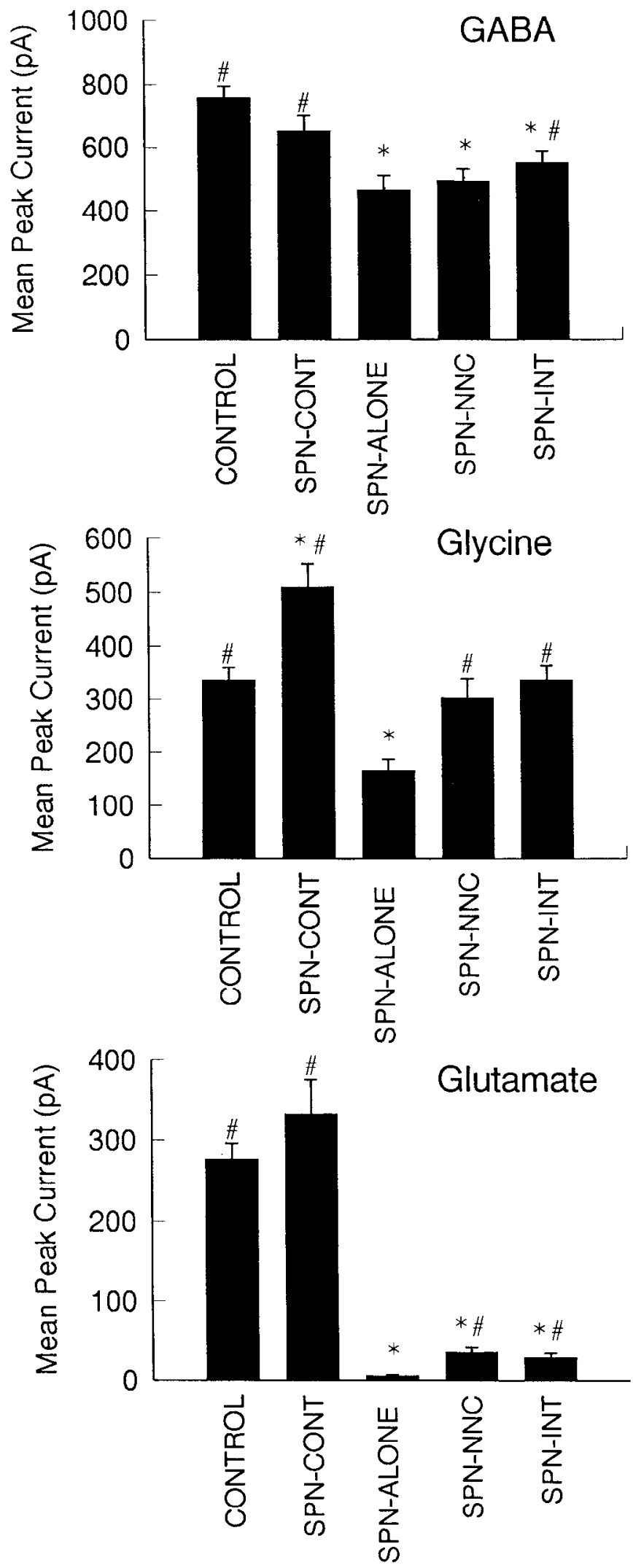

$S P N-I N T$, SPNs and interneurons only (non-neuronal cells eliminated with ARA-A). The ordinate represents the mean peak current measured in 75 or more cell from at least 3 platings for each condition. Error bars represent SEM. Values with an asterisk were significantly different from control $(p<0.005)$, while values with a \# were significantly different from SPNs alone $(p<0.005)$. All other comparisons were insignificant $(p>0.05)$. 
mained significantly lower than those of SPNs in mixed spinalcord cell cultures $(p<0.0001)$. Mean peak GABA current under this experimental condition, in fact, was not significantly different from those of sorted cells $(p>0.25)$. The GABA responsiveness of SPNs grown in culture with only interneurons was also lower than that of SPNs grown in control cultures $(p$ $<0.001$ ), but the responsiveness of these cells was slightly elevated above SPNs grown alone $(p<0.02)$. Glutamate currents in SPNs grown with either non-neuronal cells or interneurons alone were much smaller than glutamate currents in control cultures $(p<0.0001)$. In addition, the mean peak glutamate currents in SPNs in culture with either non-neuronal cells or interneurons were significantly larger than in SPNs in cultures of sorted SPNs alone $(p<0.0001)$. In contrast to both GABA and glutamate, the peak current responses to glycine of SPNs grown either with only non-neuronal cells or with only interneurons were not significantly different from those of SPNs in mixed spinal cord cell cultures $(p>0.3)$. Thus, the cellular interactions that regulate responsiveness to these 3 transmitters appear to differ.

These data also provide additional evidence against the earlier suggestion that the changes in responsiveness to GABA and glycine seen in sorted SPNs might be attributable exclusively to changes in cell morphology. The peak GABA currents of SPNs in SPN-NNC cultures were equivalent to those of SPNs in cultures with only sorted cells (both were equally low). These SPNs, however, had morphological characteristics that did not differ from controls. Thus, the presence of non-neuronal cells could induce normal morphological characteristics but could not induce GABA responsiveness. We conclude that the responsiveness of SPNs to GABA is not determined primarily by cell size, but rather, by interactions with other cells. Similar considerations indicate that glycine responsiveness is also not regulated primarily by cell size. SPNs in SPN-INT cultures were smaller than normal, and yet, they had glycine responsiveness that was indistinguishable from that of control SPNs in mixed spinal-cord cell cultures. In conclusion, while the morphological characteristics of SPNs were regulated by non-neuronal cells, the responsiveness of SPNs to all 3 amino acid neurotransmitters was regulated by interactions with both non-neuronal cells and interneurons.

Responses of SPNS to GABA, glycine, and glutamate are not regulated by sympathetic ganglion cells

Neurotransmitter receptors on some peripheral ganglion cells are known to be regulated by target cells as well as by afferent input (Jacob and Berg, 1987). We wondered, therefore, whether the presence of target sympathetic ganglion cells might affect the responsiveness of SPNs in culture to the 3 amino acid transmitters. We studied the responsiveness of labeled SPNs from mixed spinal-cord cell cultures that were cocultured with sympathetic ganglion cells at a ratio of 1 SPN per 10-100 ganglion cells. The presence of target cells had no significant effect on the overall responsiveness (pA) to GABA, glycine, or glutamate (GABA-SPN alone: $756 \pm 36$, SPN-SGC: $831 \pm 81, p>0.40$; glycine-SPN alone: $335 \perp 25$, SPN-SGC: $352 \perp 78, p>0.15$; glutamate-SPN alone: $277 \pm 19$, SPN-SGC: $264 \pm 23, p>$ $0.20)$.

\section{Possible mechanisms of neurotransmitter regulation}

The results of this study so far demonstrate that both interneurons and non-neuronal cells regulate the responsiveness of chick
SPNs to the 3 amino acid neurotransmitters, and that nonneuronal cells influence SPN morphology. They do not, however, address the question of the mechanisms underlying these regulatory interactions. Non-neuronal cells and interneurons might affect the neurotransmitter responsiveness of SPNs in a number of different ways. It is possible that their effects are exerted through the release of soluble factors. Alternatively, it is also possible that physical contact between the different cell types is required. We performed a series of experiments to test whether the cell interactions were mediated by soluble factors, or whether direct interaction through cell contact at synaptic or nonsynaptic junctions was necessary.

Tests of the role of soluble factors. One class of soluble factors that interneurons are known to release are their neurotransmitters. We hypothesized that neurotransmitters might regulate responsiveness by some process that involves interacting with receptors that are already present on the cell surface. To test this idea, we added specific receptor antagonists at a concentration sufficient to completely block the response to a halfmaximal concentration of each transmitter $(100 \mu \mathrm{M}$ GABA, 250 $\mu \mathrm{M}$ glycine, $50 \mu \mathrm{M}$ glutamate). The antagonists used were 100 $\mu \mathrm{M}$ bicuculline (GABA), $1 \mathrm{~mm}$ strychnine (glycine), or $1 \mathrm{~mm}$ kynurenic acid (glutamate). Because interneurons raised the responsiveness of SPNs to all 3 transmitters, the prediction was that responsiveness should have been lower in the presence of antagonists. However, the presence of antagonists did not have an effect on the responsiveness of SPNs to any of the neurotransmitters (GABA-control: $756 \pm 36$, bicuculine: $760 \pm 81$, $p>0.70$; glycine-control: $231 \pm 21$, strychnine: $308 \pm 57, p$ $>0.4$; glutamate-control: $139 \pm 11$, kynurenic acid: $167 \pm$ $28, p>0.90$ ). It is not likely, therefore, that the regulatory effect of interneurons is due to the release of the neurotransmitters, which then act at their receptors. This does not rule out the possibility, however, that neurotransmitters may regulate responsiveness levels by acting through other binding sites that are not blocked by the specific antagonists used.

To test for unknown soluble factors, we studied the responsiveness of sorted SPNs grown alone in CM (medium conditioned by mixed spinal-cord cells) for 7 days. The cultures from which the CM was collected contained SPNs, interneurons, and non-neuronal cells. The mean peak GABA and glycine currents $(\mathrm{pA})$ recorded in sorted SPNs grown in CM were not significantly different from SPNs grown alone without CM (GABA-SPN alone: $464 \pm 45$, SPN alone + CM: $579 \pm 97, p>0.2$; glycineSPN alone: $165 \pm 21$, SPN alone + CM: $182 \pm 42, p>0.4$ ). In contrast, the glutamate responsiveness of sorted cells grown in CM showed a modest elevation (SPN alone, $6 \pm 2$; SPN alone $+\mathrm{CM}, 29 \pm 12 ; p<0.02$ ), though the responsiveness was still much lower than in control cultures $(277 \pm 19, p<$ 0.0001 ). The effect of $\mathrm{CM}$ on glutamate responsiveness was quite similar to the effect of interneurons alone or non-neuronal cells alone on SPNs. These experiments are therefore consistent with the possibility that 1 of these cell types might act by a diffusible factor. On the other hand, the $\mathrm{CM}$ was derived from cultures containing both interneurons and non-neuronal cells, yet the glutamate responsiveness was much lower than when both cell types were present. It thus seems unlikely that soluble factors play a dominant role in regulating glutamate responsiveness. In summary, neither the appropriate neurotransmitter, acting at its normal binding site on a receptor-channel complex, nor CM (spinal-cord-conditioned medium) can mimic the stimulation that the combination of interneurons and spinal-cord non-neu- 
ronal cells provide in mixed cultures. An appealing explanation for these results is that cell-cell contact is needed for some of the regulatory effect of interneurons and non-neuronal cells. However, it remains possible that soluble factors are responsible for the regulation of neurotransmitter responsiveness, but that the factors are supplied locally in a concentrated form or are rapidly degraded, so that $\mathrm{CM}$ does not supply a high enough concentration of the factor to be effective. Both of these alternatives would require the cells producing the regulatory factor to be in close apposition to the responsive cell in order to avoid dilution or degradation of the active substance.

Tests of the role of activity. An alternative to a freely soluble factor is that properties inherent to the contact between SPNs and other cells regulate neurotransmitter responsiveness. Cell density under all culture conditions was high, so each SPN was most likely to contact several other cells. In the case of SPNINT interactions, it is possible that cell contact had an inductive effect because of the formation of functional synapses with attendant alterations in spike activity. Because we have already shown that non-neuronal cells can also regulate SPN responsiveness to GABA, glycine, and glutamate, we already know that regulation cannot be exclusively dependent on synaptic actions. We tested the effects of spike activity on the responsiveness of SPNs to GABA, glycine, and glutamate by growing SPNs in mixed spinal-cord cell cultures in the presence of 500 nM TTX (Fig. 6). This concentration of TTX was sufficient to block all spike activity in SPNs and in any interneurons presynaptic to them. The amplitude of the GABA and glycine responses of SPNs in mixed cultures to which TTX was added were significantly larger than those of SPNs in control cultures $(p<0.001)$. In contrast to the effect of TTX treatment on responses to GABA and glycine, the glutamate responsiveness of TTX-treated SPNs was not significantly different from the responsiveness of SPNs in control cultures $(p>0.60)$. Spike activity, therefore, may regulate the responsiveness of SPNs to GABA and glycine. It does not, however, appear to affect the responsiveness of SPNs to glutamate.

Tests of the cellular specificity of induction of transmitter responsiveness. If contact between cells is necessary for the regulation of neurotransmitter receptors, as the results of the experiments with neurotransmitter antagonists and CM suggest, then it raises the question of how specific the cell interaction must be. For instance, is each type of receptor regulated by all afferents that use the matching transmitter? The spinal cord contains interneurons that store and apparently release glutamate; some of these are thought to synapse on SPNs. Some DRG cells also store and release glutamate (Fagg and Foster, 1983), and it is probable that some of these also project to SPNs. We wondered, therefore, whether DRG cells would be able to regulate glutamate responsiveness in a manner similar to spinalcord interneurons.

By day 5 in vitro, the glutamate responsiveness of the SPNs in SPN-DRG cocultures was significantly higher than the glutamate responsiveness of SPNs in cultures of SPNs alone $(p<$ 0.0001 ; Fig. 7). However, responsiveness to glutamate in SPNDRG cultures remained much lower than that in control SPNs $(p<0.0001)$. This result is qualitatively similar to what is seen when SPNs are grown in culture with only interneurons. One interpretation of these results is that glutamate responsiveness can be regulated by the presence of glutamate-containing cells other than interneurons. As shown above, glutamate itself is not likely to regulate glutamate responsiveness; therefore, some oth-

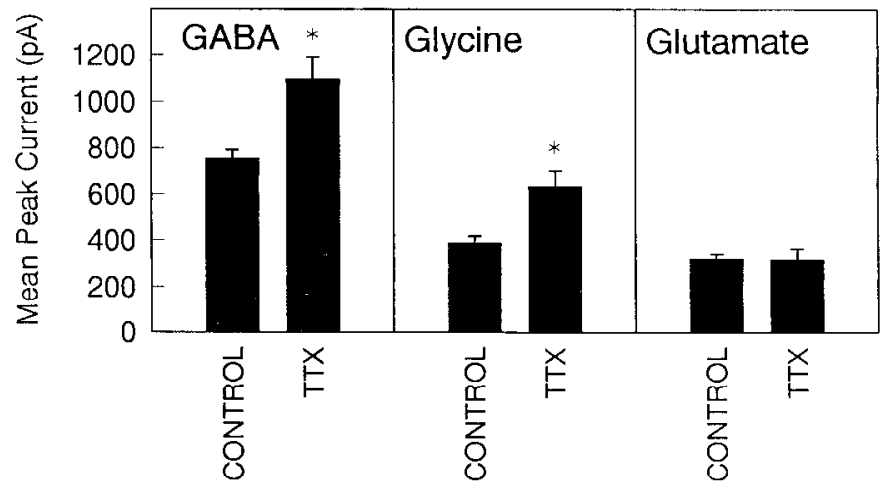

Figure 6. GABA, glycine, and glutamate currents of SPNs in TTXtreated spinal-cord cell cultures. Responses to 500 -mssec puffer applications of $100 \mu \mathrm{M}$ GABA, $250 \mu \mathrm{M}$ glycine, and $50 \mu \mathrm{M}$ glutamate were measured in SPNs in mixed spinal-cord cell cultures grown in normal neuron medium (control) or grown in neuron medium to which $500 \mathrm{~nm}$ TTX had been added. Peak current was measured in 70 or more TTXtreated cells from 4 separate platings and from more than 150 control cells from more than 10 platings. Error bars represent SEM. Mean peak glutamate currents in TTX-treated cells were not significantly different from controls $(p>0.60)$. Mean peak GABA and glycine currents in TTX-treated cultures were significantly (asterisk) larger than mean peak currents in control cultures $(p<0.005)$.

er factor common to glutamate-containing cells would be responsible for the regulatory effect. The glutamate responsiveness of SPNs in SPN-DRG cultures was actually higher than the responsiveness of SPNs in cocultures of SPN and interneurons $(p<0.0001)$. There are several reasons why this may have occurred. DRG cells were plated at very high density in these cultures $\left(8.0 \times 10^{4} \mathrm{DRGs}\right)$. Although we did not determine how many glutamatergic neurons were present, it is probable that the number of glutamatergic interneurons in spinal-cord cultures is much lower than the number of glutamatergic DRG cells in these cultures. The higher glutamate responsiveness of SPNs in SPN-DRG cultures, then, might be due to more contacts between SPNs and glutamate-containing terminals.

A second observation, however, calls this idea into question. The glycine responsiveness of sorted SPNs grown with DRG cells was increased above that found on sorted cells grown alone $(p<0.0005)$. In fact, the glycine responsiveness of these cells was not significantly different from that of SPNs grown in control cultures $(p>0.05)$. Glycine is not thought to be one of the neurotransmitters used by DRG cells. Because something in the DRG cell cultures other than glycinergic neurons seems to inducc glycinc responsiveness, it also seems possible that something other than glutamatergic neurons may be responsible for the induction of glutamate responsiveness. A likely alternative is that non-neuronal cells of the DRG are responsible for both inductive effects.

\section{Discussion}

We have used a population of identified CNS neurons to address several fundamental questions concerning the regulation of neurotransmitter receptors in the CNS. We found that (1) the levels of responsiveness of cultured SPNs to the amino acid neurotransmitters GABA, glycine, and glutamate are regulated by interactions with other cell types rather than by intrinsic mechanisms, (2) cell size does not determine the level of responsiveness of SPNs to GABA, glycine, or glutamate, (3) the presence of both interneurons and non-neuronal cells is required for the 

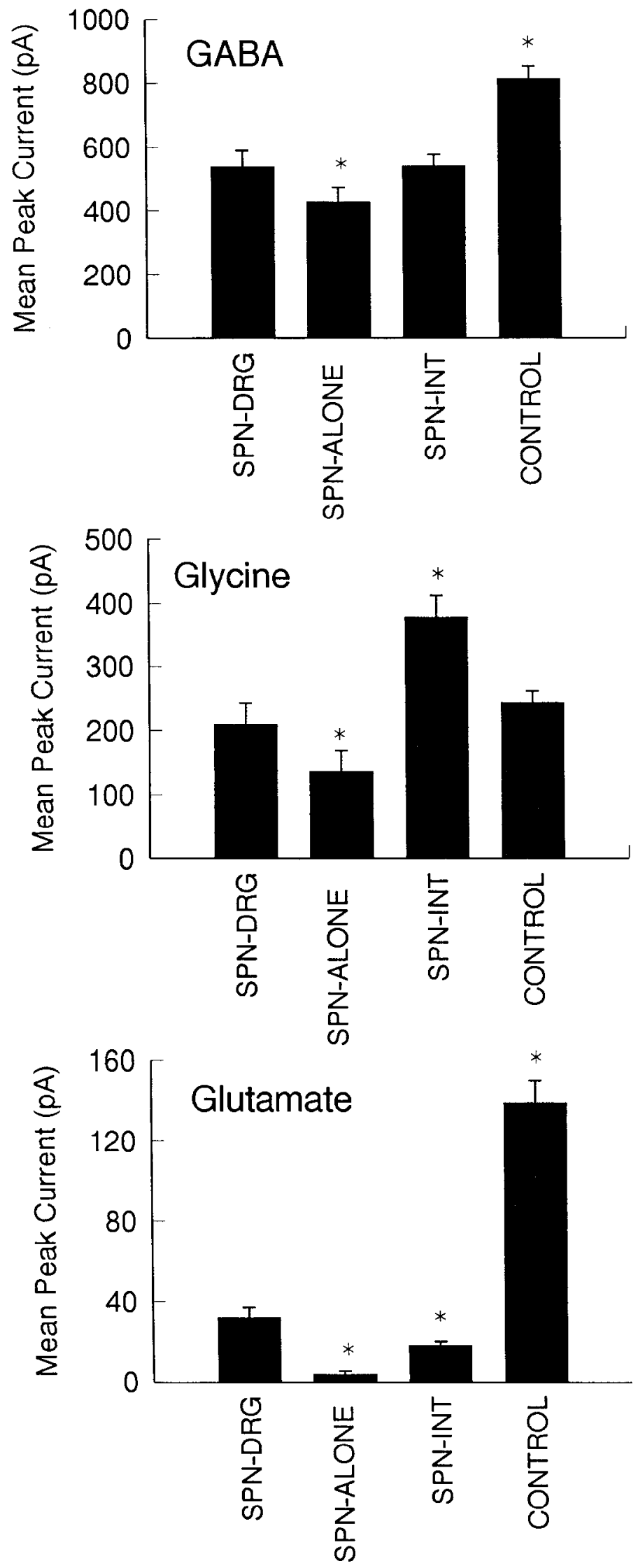

Figure 7. Effect of DRG neurons: peak current responses to $100 \mu \mathrm{M}$ GABA, $250 \mu \mathrm{M}$ glycine, and $50 \mu \mathrm{M}$ glutamate of SPNs in cultures of sorted SPNs cocultured with DRG cells $(S P N-D R G)$, in cultures of sorted SPNs alone (SPNALONE), in cultures of SPNs with interneurons expression of normal levels of GABA and glutamate responsiveness, (4) the presence of either interneurons or non-neuronal cells is sufficient to maintain normal glycine responsiveness, and (5) the addition of target cells to mixed spinal-cord cell cultures does not affect the responsiveness of SPNs to any of the amino acid neurotransmitters.

Each neurotransmitter receptor was regulated in a different manner by these cell interactions. Both cell types were necded for the expression of control levels of glutamate and GABA responsiveness by SPNs, whereas the presence of either alone was sufficient for the normal expression of glycine responsiveness. The regulation of GABA and glutamate responsiveness by non-neuronal cells and interneurons also differed. The biggest difference was the magnitude of the change in responses when both interneurons and non-neuronal cells were absent. GABA responses were about $60 \%$ of control values in SPN-alone cultures, while glutamate responses were only $2 \%$ of control values in SPN-alone cultures. Furthermore, the addition of either nonneuronal cells or interneurons resulted in glutamate currents that were significantly larger than those of SPNs in SPN-alone cultures. GABA currents, on the other hand, were elevated slightly by the presence of interneurons alone, but not at all by the presence of non-neuronal cells alone.

The smaller GABA, glycine, and glutamate currents in SPNs in cultures of sorted cells alone could be explained in a number of different ways. One appealing explanation is that there are simply fewer neurotransmitter receptors on the surface of sorted SPNs. However, the changes in mean peak currents might also be due to (1) a change in the affinity of the agonists for their receptors, (2) a change in the reversal potential of receptorassociated channels, or (3) a change in the mean open time or unitary conductance of individual channels. Of these 3 alternative explanations to a change in receptor number, the change that has been seen quite often for other receptors is a change in single-channel properties. No single-channel recording was performed in these experiments because the whole-cell currents in sorted cells were so small that it was clear that most patches would not contain any receptors. Therefore, it would be extremely difficult to gather sufficient data to test this possibility. However, in a number of different preparations, glutamate channels exhibit conductance substates that vary between 6 and 50 pS (O'Brien and Fischbach, 1986b; Cull-Candy and Usowicz, 1987, 1989; Jahr and Stevens, 1987; Vlachova et al., 1987). GABA-channel conductances exhibit substates that vary between 8 and 44 pS (Choi and Fischbach, 1981; Bormann et al., 1987; Levitan et al., 1988; Weiss et al., 1988; Cull-Candy and Usowicz, 1989; Smith et al., 1989), and glycine channels exhibit conductance substates between 17 and $32 \mathrm{pS}$ (Bormann et al.,

alone ( $S P N-I N T)$, and in mixed spinal-cord cell cultures (CONTROL) All data were collected from cells that had been in culture for $5 \mathrm{~d}$. $S P N$ $D R G$ data were collected from 56 cells for GABA, 55 cells for glycine, and 55 cells for glutamate and were from 3 separate platings. SPN-alone data were taken from 71 cells for GABA, 65 cells for glycine, and 60 cells for glutamate and were from 6 separate platings. SPN-INT data were collected from 100 cells for GABA, 100 cells for glycine, and 93 cells for glutamate and were from 4 separate platings. Control data were collected from 330 cells for GABA control, 257 cells for glycine control, and 279 cells for glutamate control. Error bars represent SEM. Mean peak current values that were significantly different from their values in coculture with DRG cells $(p<0.005)$ are marked with an asterisk. The values without asterisks did not differ significantly $(p>0.05)$. 
1987; Smith et al., 1989). The mean open times of the different conductance states also vary. Therefore, it is quite possible that some portion of the changes in mean peak current that were seen in SPNs alone could be accounted for by changes in singlechannel properties.

Although we were able to culture SPNs from relatively young embryos, we were not able to obtain SPNs before they had any interaction with target cells, intrasegmental afferents, and nonneuronal cells. Therefore, we were not able to determine whether the initial expression of neurotransmitter receptors on SPNs is intrinsically or extrinsically regulated. We could, however, determine whether the level of responsiveness to various neurotransmitters observed in culture was intrinsically regulated or if it depended on interactions with other cells. To ask whether receptors are regulated intrinsically or extrinsically in culture, one would ideally want to study SPNs either singly in culture or at densities low enough to make them nominally alone in culture. We were not able to do this with SPNs because SPNs do not survive for longer than $24 \mathrm{hr}$ in culture at low density. We could, however, separate SPNs from other cell types and study them in homotypic cultures at a standard density. The observation that homotypic cultures of SPNs without other cell types had low responsiveness to GABA, glycine, and glutamate shows not only that the receptors for these neurotransmitters are not intrinsically regulated, but also that they are not regulated by interactions with other SPNs because the sorted SPNs grown alone were plated at a density that was sufficient to allow adjacent SPNs to contact each other.

The responsiveness of SPNs to the 3 amino acid neurotransmitters was regulated by both non-neuronal cells and interneurons, but not by target cells. The regulation of receptors on these CNS cells, therefore, differs strikingly in this regard from the regulation of ACh receptors on some peripheral ganglion cells whose target cells have a large effect (Jacob and Berg, 1987). Because both non-neuronal cells and interneurons are required to obtain control levels of responsiveness to GABA and glutamate, it appears that some interaction of all 3 cell types (SPNs, interneurons, and non-neuronal cells) is needed for normal levels of responsiveness to GABA and glutamate. In the case of glutamate, the effect appeared to be synergistic in that the presence of both non-neuronal cells and interneurons produced responses that were much larger than the sum of the increases seen when either non-neuronal cells alone or interneurons alone were added to SPNs. There are precedents for synergism in trophic effects and in the regulation of neurotransmitters and their synthesizing enzymes. For example, afferent and target cells act synergistically to support the survival of cultured embryonic spinal motor neurons (Dohrmann et al., 1987), and both target and non-neuronal cells are important in the survival of retinal ganglion cells (Armson et al., 1987). The interaction between interneurons and non-neuronal cells in the regulation of responsiveness to GABA and glutamate by SPNs might be due to selective survival of interneurons. It is possible that GABA- and glutamate-releasing interneurons arc nccessary for normal levels of responsiveness to these neurotransmitters, and that non-neuronal cells are needed for the survival of the interneurons that release these 2 neurotransmitters. These cells would be selectively eliminated in cultures containing only SPNs and interneurons. A second possible explanation for the interaction between interneurons and non-neuronal cells in their effects on the responsiveness of SPNs to GABA and glutamate is suggested by the morphological changes that occur when non- neuronal cells are present. SPNs grown with non-neuronal cells have much more extensive dendritic trees than SPNs grown only with interneurons. Presumably, interneurons growing in cocultures that have non-neuronal cells present have a much greater probability of contacting SPNs. Thus, the neuronal component of induction of transmittcr responsivencss would bc cxpected to be enhanced in these cultures.

Our results are similar in many ways to those obtained by O'Brien and Fischbach (1986c) for sorted versus unsorted motor neurons from embryonic chick spinal cords. They found that glutamate responsiveness in sorted cells was about $50 \%$ of that found in cultures containing motor neurons, interneurons, and non-neuronal cells. The GABA and glycine sensitivities of sorted cells in this case, however, were normal. One possible difference between the culture conditions used by these investigators and those used here that may account for some of the differences between the results is that all of their cultures, including those of sorted cells, were necessarily grown in coculture with myotubes because motor-neuron survival is dependent on the presence of target cells.

In addition to changes in responsiveness to the amino acid neurotransmitters, we also noted a change in morphology in SPNs grown alone. Cell-body size, cell-surface area, and the number of major processes were all significantly different from SPNs in mixed spinal-cord cell cultures. These changes are attributable to the absence of non-neuronal cells. There are many examples of the dependence of neurons on non-neuronal cells for normal morphology. Although intrinsic factors appear to play an important role in the determination of neuronal morphology (Banker and Cowan, 1979), the presence of glial cells has been found to be important for the final determination of neuronal form. Sympathetic ganglion cells in culture require the presence of Schwann cells for the development of a dendritic tree comparable to that seen in vivo (Johnson et al., 1989). The requirement for non-neuronal cells may even be region specific, because it has been suggested that striatal and mesencephalic neurons in culture have a more elaborate dendritic morphology when they are plated on non-neuronal cells from their own part of the brain (Denis Domini et al., 1984; Chamak et al., 1987). The presence of target cells and afferents has also been demonstrated to influence dendritic morphology (Caviness and Rakic, 1978; Stanfield and Cowan, 1979; Berry, 1982).

We undertook these experiments with the idea that the regulation of transmitter receptors would most likely be very closely related to the formation of functional synapses. Our results suggest that the situation is not nearly this simple. This was first suggested by the observation reported in the preceding paper (Clendening and Hume, 1990) that the level of responsiveness of SPNs to neurotransmitters is not closely correlated with the presence or absence of demonstrable synaptic inputs. The results in this paper further emphasize the complexity of receptor regulation. First SPNs in SPN-alone cultures maintained their responsiveness to GABA and glycine at about the level they had when they were placed into culture. Thus, presynaptic partners are not necessary for continued low-level expression of responsiveness to these 2 neurotransmitters. Second, and more dramatic, glycine responsiveness could rise to control levels in the absence of any presynaptic neurons, as long as the appropriate non-neuronal cells were present. Nonetheless, our experiments demonstrate that, under appropriate conditions, spinal interneurons can have a powerful inductive effect on neurotransmitter responsiveness. Although all changes in neurotransmitter 
responsiveness cannot be related exclusively to synapse formation, it still seems likely that the formation of synapses play a major role.

\section{References}

Adler JE, Black IB (1984) Development and regulation of substance $\mathrm{P}$ in sensory neurons in vitro. Dev Biol 102:417-425.

Adler JE, Black IB (1985) Sympathetic neuron density differentially regulates transmitter phenotypic expression in culture. Proc Natl Acad Sci USA 82:4296-4300.

Anderson MJ, Cohen MW (1977) Nerve-induced and spontaneous redistribution of acctylcholine receptors on cultured muscle cells. J Physiol (Lond) 268:757-773.

Anderson MJ, Cohen MW, Zorychta E (1977) Effects of innervation on the distribution of acetylcholine receptors on cultured muscle cells. J Physiol (Lond) 268:731-756.

Armson PF, Bennett MR, Raju TR (1987) Retinal ganglion cell survival and neurite regeneration requirements: the change from Muller cell dependence to superior colliculi dependence during development. Dev Brain Res 32:207-216.

Banker GA, Cowan MW (1979) Further observations on hippocampal neurons in dispersed cell cultures. J Comp Neurol 187:467-494.

Banker GA, Waxman AB (1988) Hippocampal neurons generate natural shapes in cell culture. In: Intrinsic determinants of neuronal function and form (Lasek RJ, Black MM, eds), pp 61-82. New York: Liss.

Beaudoin AR (1955) The development of lateral motor column cells in the lumbosacral cord in Rana pipiens. I. Normal development and development following unilateral limb ablation. Anat Rec 121:8196.

Bergey GK, Fitzgerald SC, Schier BK, Nelson PG (1981) Neuronal maturation in mammalian cell cultures is dependent on spontaneous electrical activity. Brain Res 207:49-58.

Berry M (1982) Cellular differentiation: development of dendritic arborizations under normal and experimentally altered conditions. Neurosci Res Program Bull 20:451-460.

Bevan S, Steinbach JH (1977) The distribution of alpha-bungarotoxin binding sites on mammalian skeletal muscle developing in vivo. $\mathrm{J}$ Physiol (Lond) 267:195-213.

Black IB, Hendly IA, Iversen LL (1971) Trans-synaptic regulation of growth and development of adrenergic neurons in a mouse sympathetic ganglion. Brain Res 34:229-240.

Black IB, Joh TH, Reis DJ (1974) Accumulation of tyrosine hydroxylase molecules during growth and development of the superior cervical ganglion. Brain Res 75:133-144.

Bormann J, Hamill OP, Sakmann B (1987) Mechanism of anion permeation through channels gated by glycine and gamma-aminobutyric acid in mouse cultured neurones. J Physiol (Lond) 385:243-286.

Brookes N, Burt DR, Goldberg AM, Bierkamper GG (1980) The influence of muscle-conditioned medium on cholinergic maturation in spinal cord cell cultures. Brain Res 186:474-479.

Burden S (1977) Development of the neuromuscular junction in the chick embryo: the number, distribution, and stability of acetylcholine receptors. Dev Biol 57:317-329.

Calof AL, Reichardt LF (1984) Motoneurons purified by cell sorting respond to two distinct activities in myotube-conditioned medium. Dev Biol 106:194-210.

Caviness VS, Rakic P (1978) Mechanisms of cortical development: a view from mutations in mice. Annu Rev Neurosci 1:297-326.

Chamak B, Fellous A, Glowinski J, Prochiantz A (1987) MAP2 expression and neurite outgrowth and branching are coregulated through region-specific neuroastroglial interactions. J Neurosci 7:3163-3170.

Choi DW, Fischbach GD (1981) GABA conductance of chick spinal cord and dorsal root ganglion neurons in cell culture. J Neurophysiol 45:605-620.

Clendening B, Hume RI (1990) Expression of multiple neurotransmitter receptors by sympathetic preganglionic neurons in vitro. J Neurosci 10:3977-3991.

Cull-Candy SG, Usowicz M (1987) Multiple-conductance channels activated by excitatory amino acids in cerebellar neurons. Nature 325 : 525-528.

Cull-Candy SG, Usowicz MM (1989) Whole-current noise produced by excitatory and inhibitory amino acids in large cerebellar neurons of the rat. J Physiol (Lond) 415:533-553.

Davis MR, Constantine-Paton M, Schorr D (1983) Dorsal root ganglion removal in Rana pipiens produces fewer motoneurons. Brain Res 265:283-288.

Denis-Donini S, Glowinski J, Prochiantz A (1984) Glial heterogeneity may define the three-dimensional shape of mouse mesencephalic dopaminergic neurones. Nature 307:641-643.

Dohrmann U, Edgar D, Sendtner M, Thoenen H (1986) Muscle-derived factors that support survival and promote fiber outgrowth from embryonic chick spinal motor neurons in culture. Dev Biol 118:209221 .

Dohrmann U, Edgar D, Thoenen H (1987) Distinct neurotrophic factors from skeletal muscle and the central nervous system interact synergistically to support the survival of cultured embryonic spinal motor neurons. Dev Biol 124:145-152.

Fagg GE, Foster AC (1983) Amino acid neurotransmitters and their pathways in the mammalian central nervous system. Neuroscience 9:701-719.

Fischbach GD, Nelson PG (1977) Cell culture in neurobiology. In: Handbook of physiology: the nervous system, Vol l (Kandel E, ed), pp 719-774. Bethesda: American Physiological Society.

Frank E, Fischbach GD (1979) Early events in neuromuscular junction formation in vitro: induction of acetylcholine receptor clusters in the postsynaptic membrane and morphology of newly formed nerve-muscle synapses. J Cell Biol 83:143-158.

Furber S, Oppenheim R, Prevette D (1987) Naturally occurring neuron death in the ciliary ganglion of the chick embryo following removal of preganglionic input: evidence for the role of afferents in ganglion cell survival. J Neurosci 7:1816-1832.

Gallently NP, Svendsen CN, Isacon O, Sofroneiu MV (1989) Basal forebrain cholinergic neurons from young adult rat are not dependent on target derived factors for survival. Soc Neurosci Abstr 15:1362.

Giller EL, Neale JH, Bullock PN, Schrier BK, Nelson PG (1977) Choline acetyltransferase activity of spinal cord cell cultures increased by co-culture with muscle and by muscle-conditioned medium. J Cell Biol 74:16-29.

Godfrey EW, Schrier BK, Nelson PG (1980) Source and target cell specificities of a conditioned medium factor that increases choline acetyltransferase activity in cultured spinal cord cells. Dev Riol 77: 403-418.

Hamburger V (1958) Regression versus peripheral control of differentiation in motor hypoplasia. $\Lambda \mathrm{m} \mathrm{J} \Lambda$ nat 102:365-410.

Hamburger V, Levi-Montalcini R (1949) Proliferation, differentiation and degeneration in the spinal ganglia of the chick embryo under normal and experimental conditions. J Exp Zool 111:457-502.

Honig MG, Hume RI (1986) Fluorescent carbocyanine dye allows living neurons of identified origin to be studied in long-term cultures. J Cell Biol 103:171-187.

Jacob MH, Berg DK (1987) Effects of preganglionic denervation and postganglionic axotomy on acetylcholine receptors in the chick ciliary ganglion. J Cell Biol 105:1847-1854.

Jacob MH, Berg DK, Lindstrom JM (1984) Shared antigenic determinant between the electrophorus acetylcholine receptor and a synaptic component on chick ciliary ganglion neurons. Proc Natl Acad Sci USA 81:3223-3227.

Jahr CE, Stevens CF (1987) Glutamate activates multiple single channel conductances in hippocampal neurons. Nature 325:522-525.

Jessell TM, Siegel RE, Fischbach GD (1979) Induction of acetylcholine receptors on cultured skeletal muscle by a factor extracted from brain and spinal cord. Proc Natl Acad Sci USA 10:5397-5401.

Johnson EM, Caserta MT, Ross LL (1977) Effect of destruction of the postganglionic sympathetic neurons in neonatal rats on development of choline acetyltransferase and survival of preganglionic cholinergic neurons. Brain Res 136:455-464.

Johnson MI, Higgins D, Ard MD (1989) Astrocytes induce dendritic development in cultured sympathetic neurons. Dev Brain Res 47: 289-292.

Kessler JA (1984a) Environmental co-regulation of substance P, somatostatin and neurotransmitter synthesizing enzymes in cultured sympathetic neurons. Brain Res 321:155-159.

Kessler JA (1984b) Non-neuronal cell conditioned medium stimulates peptidergic expression in sympathetic and sensory neurons in vitro. Dev Biol 106:61-69.

Kessler JA, Adler JE, Bohn MC, Black IB (1981) Substance P in 
principal sympathetic neurons: regulation by impulse activity. Science 214:335-336.

Kessler JA, Adler JE, Bell WO, Black IB (1983) Substance P and somatostatin metabolism in sympathetic and special sensory ganglia in vitro. Neuroscience 9:309-318.

Kruskal WH, Wallis WA (1952) Use of ranks in one-criterion variance analysis. J Amer Stat Assoc 47:583-621.

Levitan ES, Blair LA, Dionne VE, Barnard EA (1988) Biophysical and pharmacological properties of cloned $\mathrm{GABA}_{\mathrm{A}}$ receptor subunits expressed in Xenopus oocytes. Neuron 1:773-781.

Mudge AW (1981) Effect of chemical environment on levels of substance $P$ and somatostatin in cultured sensory neurones. Nature 292: 764-766.

O'Brien RJ, Fischbach GD (1986a) Isolation of embryonic chick motoneurons and their survival in vitro. J Neurosci 6:3265-3274.

O'Brien RJ, Fischbach GD (1986b) Characterization of excitatory amino acid receptors expressed by embryonic chick motoneurons in vitro. J Ncurosci 6:3275-3283.

O'Brien RJ, Fischbach GD (1986c) Modulation of embryonic chick motoneuron glutamate sensitivity by interneurons and agonists. $\mathbf{J}$ Neurosci 6:3290-3296.

Okado N, Oppenheim RW (1984) Cell death of motoneurons in the chick embryo spinal cord. IX. The loss of motor neurons following the removal of afferent inputs. J Neurosci 4:1639-1652.

Patterson PH (1978) Environmental determination of autonomic neurotransmitter functions. Annu Rev Neurosci 1:1-17.

Patterson PH, Chun LLY (1974) The influence of non-neuronal cells on catecholamine and acetylcholine synthesis and accumulation in cultures of dissociated sympathetic neurons. Proc Natl Acad Sci USA $71: 3607-3610$.
Patterson PH, Chun LLY (1977) The induction of acetylcholine synthesis in primary cultures of dissociated rat sympathetic neurons. I. Effects of conditioned medium. Dev Biol 56:263-280.

Prestige MC (1967) The control of cell number in the lumbar ventral horn during the development of Xenopus laevis tadpoles. J Embryol Exp Morphol 18:359-387.

Role LW (1988) Neural regulation of acetylcholine sensitivity in embryonic sympathetic neurons. Proc Natl Acad Sci USA 85:28252829.

Smith KE, Kessler JA (1988) Non-neuronal cell-conditioned medium regulates muscarinic receptor expression in cultured sympathetic neurons. J Neurosci 8:2406-2413.

Smith SM, Zorec R, McBurney RN (1989) Conductance states activated by glycine and GABA in rat cultured spinal neurones. J Membr Biol 108:45-52.

Stanfield BB, Cowan WM (1979) The morphology of the hippocampus and dentate gyrus in normal and reeler mice. $\mathrm{J}$ Comp Neurol 185 : $393-422$.

Varon S, Raiborn C, Burnham P (1977) Comparative effects of nerve growth factor and ganglionic nonneuronal cells on purified mouse ganglionic neurons in culture. J Neurobiol 5:355-371.

Vlachova V, Vyklicky L, Vyklicky L, Jr, Vyskocil F (1987) The action of excitatory amino acids on chick spinal cord neurones in culture. $J$ Physiol (Lond) 386:425-438.

Weiss DS, Barnes EM, Hablitz JJ (1988) Whole-cell and single-channel recordings of GABA-gated currents in cultured chick cerebral neurons. J Neurophysiol 59:495-513.

Zurn AD, Mudry F (1986) Conditions increasing the adrenergic properties of dissociated chick superior cervical ganglion neurons grown in long-term culture. Dev Biol 117:365-379. 